\title{
Thorium-based plutonium incineration in the I'S-LWR
}

\author{
Dan Kotlyar*, Geoffrey T. Parks, Eugene Shwageraus \\ Department of Engineering, University of Cambridge, Cambridge CB2 1PZ, United Kingdom
}

\section{A R T I C L E I N F O}

\section{Article history:}

Received 6 July 2015

Received in revised form 12 July 2016

Accepted 22 August 2016

Available online 27 August 2016

\section{Keywords:}

$\mathrm{I}^{2} \mathrm{~S}-\mathrm{LWR}$

Thorium cycles

Plutonium incineration

WIMS

PANTHER

\begin{abstract}
A B S T R A C T
This paper presents an analysis of a homogeneous thorium-plutonium fuel cycle developed for the Integral Inherently Safe LWR ( $\left.I^{2} S-L W R\right)$. The $I^{2} S-L W R$ is an advanced $2850 \mathrm{MWt}$ integral PWR with inherent safety features. Its baseline fuel and cladding materials are $\mathrm{U}_{3} \mathrm{Si}_{2}$ and advanced FeCrAl steel, respectively. The advanced steel cladding can withstand longer exposure periods with significantly lower degradation rates compared to traditional $\mathrm{Zr}$-based alloys. However, longer fuel cycles would require higher fuel enrichment, and this is currently limited to $5^{\mathrm{w}_{\%}}$ in the $\mathrm{I}^{2} \mathrm{~S}$-LWR. Therefore, an alternative thorium-plutonium mixed oxide (TOX) fuel cycle is investigated. In principle, the TOX fuel cycle has no fissile content limitation and becomes even more attractive for long irradiation periods, due to the efficient build-up of ${ }^{233} \mathrm{U}$, which increases its cumulative energy share and hence decreases the initial Pu requirements per unit of energy produced by the fuel. Current Pu recycling practice in the form of $U_{-}$ $\mathrm{Pu}$ mixed oxide (MOX) fuel is not well-suited for Pu disposition due to continuous Pu production from ${ }^{238} \mathrm{U}$. This study compares the TOX and MOX cores in terms of efficiency of Pu disposition. The results show that the burnt Pu fraction in the TOX cycle is much higher, and could be further enhanced for longer irradiations ( $100 \mathrm{MWd} / \mathrm{kg}$ or more).
\end{abstract}

(c) 2016 Published by Elsevier Ltd. This is an open access article under the CC BY license (http://creativecommons.org/licenses/by/4.0/).

\section{Introduction}

This research focuses on thorium-plutonium fuel cycle options for the Integral Inherently Safe Light Water Reactor ( $I^{2} S$-LWR). The $\mathrm{I}^{2} \mathrm{~S}$-LWR concept (Petrovic, submitted for publication, 2014; Salazar and Franceschini, 2014) is a Gen III+ large scale (i.e. $1 \mathrm{GWe}$ ) pressurized water reactor (PWR). The preliminary design of the $I^{2} S-L W R$ is being carried out by a consortium made up of universities (Michigan, Virginia Tech, Tennessee, Florida Institute of Technology, Idaho, Morehouse College, Cambridge, Politecnico di Milano, Zagreb), Idaho National Laboratory, Westinghouse and Southern Nuclear Company. The project is led by the Georgia Institute of Technology and the US contributions are funded by the Department of Energy through a Nuclear Energy University Programs (NEUP) Integrated Research Project (IRP).

Innovative features of this PWR concept include: an integral primary circuit, a fully passive decay heat removal system that provides indefinite cooling capability, and the use of new materials. Novel materials that were originally chosen for this design include $\mathrm{U}_{3} \mathrm{Si}_{2}$ pellets within advanced FeCrAl steel cladding. The project also seeks to address issues such as sustainability (i.e. fuel utilization and waste minimization) and proliferation resistance. This

\footnotetext{
* Corresponding author.

E-mail address: dk494@cam.ac.uk (D. Kotlyar).
}

motivates our current research, which focuses on designing and assessing an alternative thorium-based fuel cycle for the $\mathrm{I}^{2} \mathrm{~S}$-LWR.

Bearing in mind that as reported by the IAEA (1998) large stockpiles of civil separated plutonium have been accumulated, Gen III or III + power reactors could be attractive candidates for $\mathrm{Pu}$ incineration. According to this IAEA report (INFCIRC/549) the largest plutonium stockpile is in the UK and is estimated to be around 112 tonnes. The continuing growth of separated plutonium stockpiles around the world poses proliferation and environmental risks.

Current experience (IAEA, 2003) of plutonium recycling is mostly limited to the mixed oxide U-Pu (MOX) fuel. This approach is not a particularly efficient means of $\mathrm{Pu}$ disposition, since $\mathrm{Pu}$ destruction is accompanied by simultaneous generation of new $\mathrm{Pu}$ from ${ }^{238} \mathrm{U}$. The use of Th-Pu mixed oxide (TOX) fuel to increase $\mathrm{Pu}$ incineration efficiency has been considered in the past by, among others, Galperin et al. (2000), Galperin and Raizes (1997), Shwageraus et al. (2003), Fridman and Kliem (2011) and Bjork and Fhager (2009). These studies have demonstrated improvements in Pu consumption by transitioning to the TOX cycle, with the majority investigating the utilization of Pu fuel in a typical or modified LWR core, assuming typical irradiation periods of $\sim 50 \mathrm{MWd} / \mathrm{kgHM}$. These irradiation periods were so chosen because, in existing LWRs, discharge burnup is limited primarily by the performance of the Zircaloy cladding, the mechanical 
properties of which degrade with burnup, and hence limit the maximum achievable fuel burnup.

In the $\mathrm{I}^{2} \mathrm{~S}$-LWR design, an advanced $\mathrm{FeCrAl}$ steel is envisioned as the cladding material. There are on-going tests to evaluate its mechanical properties, such as yield strength and ultimate strength, under irradiation. However, a recent study (Terrani et al., 2012) indicates that such cladding materials can withstand longer irradiation periods with much lower degradation of their mechanical properties than standard $\mathrm{Zr}$ alloys. Transitioning from $\mathrm{Zr}$ to advanced steel alloys offers the opportunity to improve the economic performance of the plant by enabling longer irradiation periods.

However, since longer fuel cycles would require enrichments higher than the existing design limit (i.e. more than $5^{\mathrm{w}_{\%}}$ of ${ }^{235} \mathrm{U}$ ), extending the fuel burnup with enriched $\mathrm{UO}_{2}$ or $\mathrm{U}_{3} \mathrm{Si}_{2}$ in the $\mathrm{I}^{2} \mathrm{~S}$ LWR design is not possible. TOX fuel does not have such limitations and thus offers an alternative solution. An additional advantage of TOX fuel is that ${ }^{233} \mathrm{U}$ will be continuously produced through neutron captures in ${ }^{232} \mathrm{Th}$ and in time contributes a significant fraction of the energy produced. This fuel cycle strategy could also replace the current approach to incinerate $\mathrm{Pu}$ in the form of MOX - an approach that is inefficient due to the continuous production of $\mathrm{Pu}$ from ${ }^{238} \mathrm{U}$.

Recent studies (Shwageraus and Feinroth, 2011) investigated the potential use of silicon carbide cladding (Feinroth et al., 2002) to extend the burnup of TOX fuel. Although this study presented only basic lattice physics analysis, it clearly highlighted the motivation (i.e. improved Pu consumption) for extending the discharge burnup.

The main objective of the current work is to investigate $\mathrm{Pu}$ incineration efficiency for the specific $\mathrm{I}^{2} \mathrm{~S}$-LWR case by extending the burnup beyond $90 \mathrm{MWd} / \mathrm{kgHM}$. This, in turn, will allow considerably more energy to be extracted from ${ }^{233} \mathrm{U}$, which is continuously being bred from thorium. Moreover, the Pu burnup would be 'deeper', as the final-to-initial Pu content ratio decreases with burnup. Finally, the Th-Pu fuel cycle is more proliferationresistant since the fraction of $\mathrm{Pu}$ isotopes with high decay heats (i.e. ${ }^{238} \mathrm{Pu}$ and ${ }^{241} \mathrm{Pu}$ ) increases with burnup. It should also be mentioned that ${ }^{233} \mathrm{U}$ bred from ${ }^{232} \mathrm{Th}$ has a certain degree of proliferation self-protection due to high energy $\gamma$ emitters present in its transmutation chain (Laughter et al., 2002).

The assessment of the $100 \%$ TOX and 100\% MOX loaded cores and associated fuel cycles was performed through full 3D modelling of the corresponding cores. The feasibility of nearly doubling the burnup of the $I^{2} S$-LWR fuel through the use of TOX fuel was confirmed. The results indicate that, compared to the traditional MOX approach, the TOX fuel cycle is favourable in terms of core behaviour (e.g. cycle length and power peaking) and $\mathrm{Pu}$ incineration.

\section{Calculation methodology}

The analysis of the $\mathrm{I}^{2} \mathrm{~S}$-LWR thorium-based core design was performed using the WIMS-PANTHER core physics package. WIMS10 (Newton et al., 2008) was used for lattice data generation by employing a 172-group JEFF3.1-based library. WIMS uses the method of characteristics and collision probability to obtain the transport solution needed to generate homogenised parameters for each fuel type. WIMS has been extensively verified and is capable of modelling fast and thermal systems, see for example (Lindley et al., 2016).

Full-core analyses for both the MOX and TOX fuel cycles were performed with the nodal diffusion code PANTHER (Morrison, 2003). PANTHER includes a thermal-hydraulic module to solve the heat conduction-convection problem.
In PANTHER, a 3-batch reloading scheme was iteratively applied to both the TOX and MOX core designs until the main core parameters converged and an equilibrium cycle was reached.

The reactor-grade $\mathrm{Pu}$ isotopic vector was taken from typical LWR discharge fuel with initial $4.5^{w_{\%}}$ enrichment (Shwageraus et al., 2003), $50 \mathrm{MWd} / \mathrm{kg}$ burnup and 10 years of cooling following discharge. The plutonium vector is shown in Table 1.

\section{Core and fuel design}

\subsection{Fuel assembly geometry}

The core design includes fresh and burned assemblies. The assemblies also contain different burnable poison loadings in the form of integral fuel burnable absorber (IFBA). The ${ }^{10} \mathrm{~B}$ concentration used in the IFBA rods is $0.984 \mathrm{mg} / \mathrm{cm}$ ( $2.5 \mathrm{mg} / \mathrm{in})$. Radial assembly loading patterns are used to flatten the core power distribution as depicted in Fig. 1. Each assembly axially consists of $3.6576 \mathrm{~m}$ (144 in) of homogeneous fuel between top and bottom reflectors. The $I^{2} S$-LWR aims to achieve a power density $40 \%$ higher than that of a 2-loop Westinghouse PWR core. To achieve this objective, the assembly array was modified to a $19 \times 19$ square pitch lattice, as shown in Fig. 1. The main fuel assembly design parameters are presented in Table 2.

\subsection{Fuel management}

The 3-batch $\mathrm{I}^{2} \mathrm{~S}$-LWR thorium core loading pattern (LP) is shown in Fig. 2. No LP optimization was performed at this stage. The core LP was adapted from (Zainuddin, 2015), with the chosen LP being the one that gives the most negative moderator temperature coefficient (MTC) value. In their work, loading patterns were optimized using a multi-objective genetic algorithm (Parks, 1996) to identify trade-offs between different objective functions (e.g. radial power peaking, discharge burnup, MTC, etc.) and the corresponding LP for each optimized objective. The baseline fuel for their work was thorium-plutonium which allows us to use their findings. Optimizing for different objective functions revealed different LP strategies. In the case of minimizing MTC, especially for high plutonium content fuel, the only way to obtain a negative MTC is to place fresh fuel on the core periphery, with once and twice burnt fuel placed towards the centre of the core. This LP increases core leakage and thus amplifies the negative contribution to MTC following spectrum hardening. This LP appears to be the more favourable even with the use of burnable poisons. This is because the main contributor to positive MTC in these TOX cores is the increase in epithermal fission in ${ }^{239} \mathrm{Pu}$.

The $\mathrm{I}^{2} \mathrm{~S}$-LWR core includes 40 fresh assemblies per reload out of 121 assemblies. As shown in Fig. 2, the fresh assemblies are positioned at the outermost peripheral locations to lower the radial peaking factor and to minimize the MTC.

Table 1

Initial $\mathrm{Pu}$ isotopic vector.

\begin{tabular}{ll}
\hline Isotope & w $\%$ \\
\hline${ }^{238} \mathrm{Pu}$ & 3.18 \\
${ }^{239} \mathrm{Pu}$ & 56.35 \\
${ }^{240} \mathrm{Pu}$ & 26.62 \\
${ }^{241} \mathrm{Pu}$ & 8.02 \\
${ }^{242} \mathrm{Pu}$ & 5.83 \\
\hline
\end{tabular}




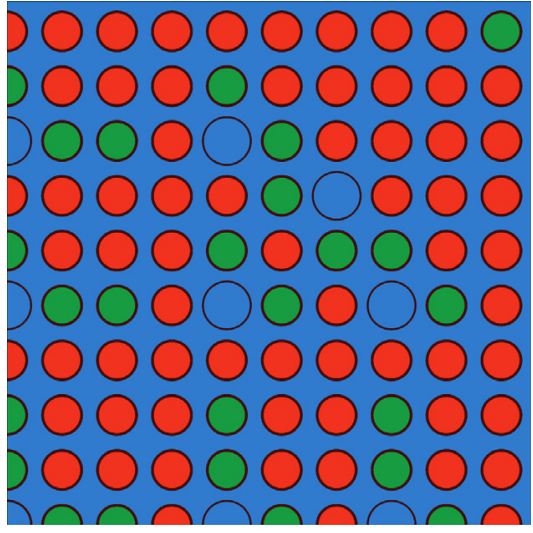

(a) 84 IFBA rods

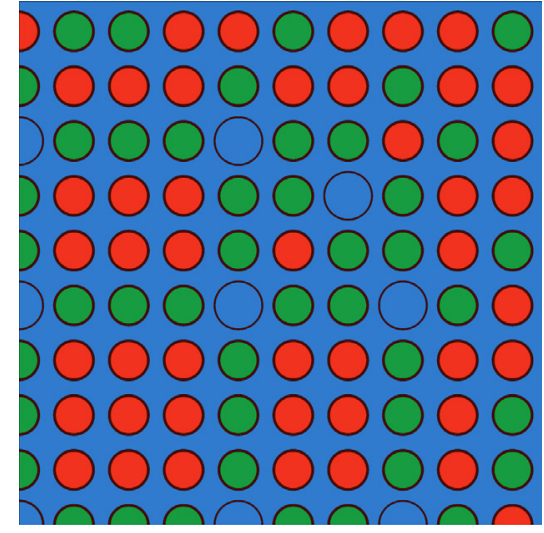

(b) 156 IFBA rods

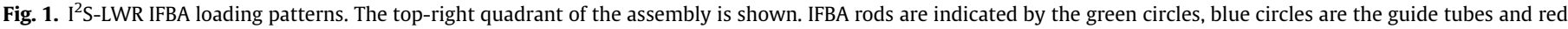

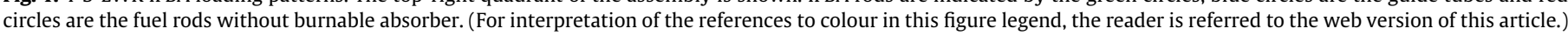

Table 2

$\mathrm{I}^{2} \mathrm{~S}$-LWR main assembly parameters.

\begin{tabular}{ll}
\hline Parameter & Value \\
\hline Power rate & $2850 \mathrm{MW}$ \\
Fuel assembly pitch & $23.1 \mathrm{~cm}$ \\
Lattice & $19 \times 19$ square \\
Control rods per assembly & 24 \\
Cladding material & FeCrAl (Terrani et al., 2012) \\
Fuel cell pitch & $1.2150 \mathrm{~cm}$ \\
Fuel pin outer radius & $0.4591 \mathrm{~cm}$ \\
Fuel pellet radius & $0.4097 \mathrm{~cm}$ \\
Guide tube inner radius & $0.5102 \mathrm{~cm}$ \\
Guide tube outer radius & $0.5476 \mathrm{~cm}$ \\
\hline
\end{tabular}

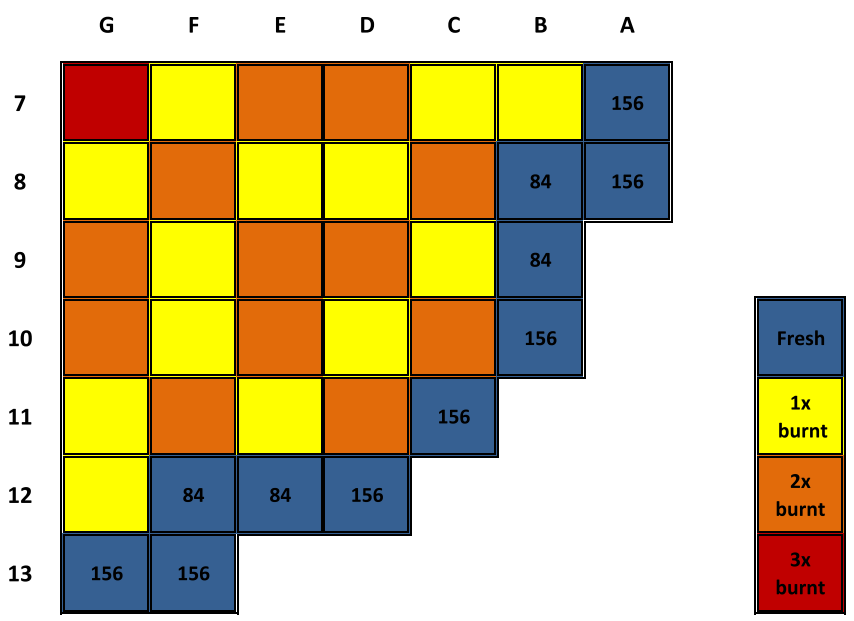

Fig. 2. Equilibrium cycle core loading pattern. The numbers indicate the number of IFBA rods in fresh fuel assemblies.

\section{Core analysis}

\subsection{Pu incineration efficiency}

This section presents the $\mathrm{Pu}$ incineration efficiency analysis results. More specifically, it illustrates the motivation for extending the fuel burnup from typical values of $50 \mathrm{MWd} / \mathrm{kg}$ to above $90 \mathrm{MWd} / \mathrm{kg}$ for the TOX case. To determine the efficiency of $\mathrm{Pu}$ burning, a wide range of volume fraction (the fraction $\mathrm{PuO}_{2}$ in the mixture) values $\left(6,8, \ldots, 20^{\mathrm{v}} \%\right)$ were considered for both the
TOX and MOX cycles. The density of $\mathrm{ThO}_{2}$ and $\mathrm{PuO}_{2}$ were set to be $95 \%$ of their theoretical values, which are $9.5 \mathrm{~g} / \mathrm{cm}^{3}$ and $10.89 \mathrm{~g} / \mathrm{cm}^{3}$ respectively. For the TOX fuel, the Pu vector (Table 1) was homogeneously mixed with $\mathrm{ThO}_{2}$. The MOX fuel was assumed to be manufactured by mixing the identical $\mathrm{Pu}$ vector with depleted $\mathrm{UO}_{2}$ fuel $\left(0.25^{\mathrm{w}} \%\right.$ of $\left.{ }^{235} \mathrm{U}\right)$.

In this stage, 3D calculations were performed by applying the $\mathrm{LP}$ described in Fig. 2. The cycle length was evaluated for each case bearing a different $\mathrm{Pu}$ volume fraction.

Fig. 3 shows that increasing the Pu volume fraction in the mixture improves the Pu utilization for both the TOX and MOX cycles. This is measured through the initial mass of Pu per unit of energy produced by the fuel. Increasing the $\mathrm{PuO}_{2}$ volume fraction allows higher burnups to be achieved (Fig. 4), which, in turn, in the TOX cycle enables efficient breeding of fissile ${ }^{233} \mathrm{U}$. The motivation to load a higher initial Pu content is to increase the discharge burnup and lower $\mathrm{Pu}$ requirements per unit of energy generated. Moreover, it can be seen that for $\mathrm{PuO}_{2}$ volume ratios above $12^{\mathrm{v}} \%$, considerably higher discharge burnups are achieved in the TOX cycle compared to the MOX cycle. This is a result of a higher build-up of fissile material in the TOX cycle, i.e. ${ }^{233} \mathrm{U}$ bred from ${ }^{232} \mathrm{Th}$ (Fig. 5). The bred ${ }^{233} \mathrm{U}$ increases the cycle length by contributing to the total energy production.

Fig. 5 presents the cumulative energy share of the most important fissile nuclides as a function of the discharge burnup. The

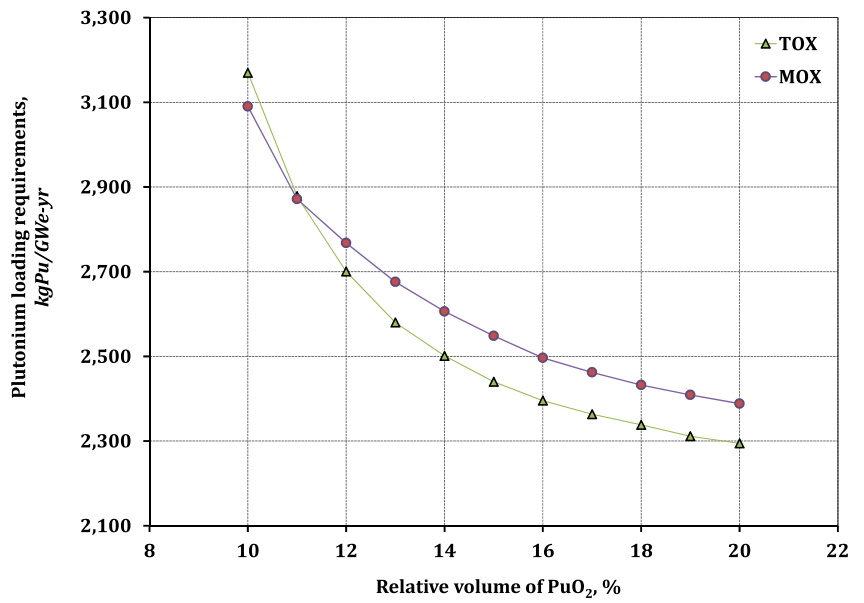

Fig. 3. Pu utilization (kg-Pu/GWe-yr) as a function of $\mathrm{PuO}_{2}$ relative volume. 


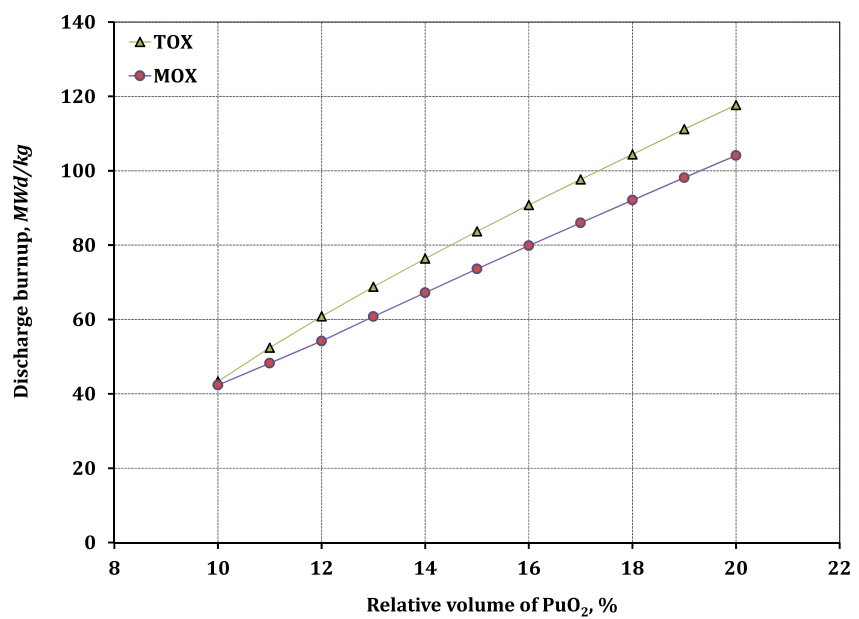

Fig. 4. Discharge burnup as a function of $\mathrm{PuO}_{2}$ relative volume.

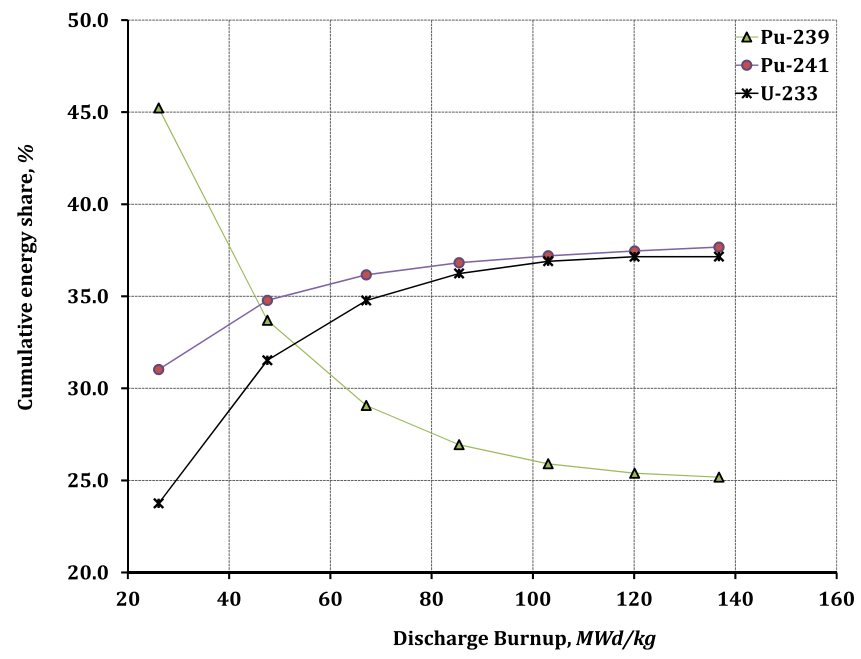

Fig. 5. Cumulative energy share of different fissile nuclides in the TOX cycle.

cumulative energy $Q_{j}$ for each fissile nuclide $j$ was calculated using Eq. (1):

$Q_{j}=\frac{\int_{0}^{T_{d}} \phi(t) \Sigma_{f, j}(t) E_{f, j} d t}{\sum_{j} \int_{0}^{T_{d}} \phi(t) \Sigma_{f, j}(t) E_{f, j} d t}$

where $T_{d}$ is the time to discharge, $\phi(t)$ is the flux at time $t, \Sigma_{f, j}(t)$ is the macroscopic fission cross-section of nuclide $j$ at time $t$ and $E_{f, j}$ is the energy released per fission of nuclide $j$.

It is important to note that the discharge burnup/time is different for different $\mathrm{Pu}$ volume fractions. Fig. 5 shows that increasing the Pu volume in the mixture increases the energy production from ${ }^{233} \mathrm{U}$, which is known to have a low build-up rate. However, when the volume fraction of $\mathrm{Pu}$ reaches $18^{\mathrm{v}} \%$, corresponding to a discharge burnup of $\sim 104 \mathrm{MWd} / \mathrm{kg}$ (Fig. 4), the total energy production from ${ }^{233} \mathrm{U}$ saturates. This also explains why $\mathrm{Pu}$ utilization eventually reaches equilibrium for high initial Pu loadings, as shown in Fig. 3.

\subsection{Determination of Pu loadings}

The results of the TOX fuel cycle analysis in the previous section showed that it is worthwhile to use higher Pu fractions due to the resulting better Pu utilization. In this section, 3D full-core analyses for the various Pu volume fractions (i.e. $10-20 \%$ ) were performed for the TOX and MOX cycles. In each case, a different discharge burnup was achieved and then used to extract the Pu concentration at the discharge point. Fig. 6 shows the percentage of Pu burnt for the different initial $\mathrm{Pu}$ loadings. These results again underline that there is a strong incentive to increase the Pu volume fraction in the mixture.

Table 3 summarizes the performance of the TOX and MOX designs in terms of discharge burnup, $\mathrm{Pu}$ incineration and $\mathrm{Pu}$ utilization. This table and the accompanying figures convey three main points:

1. Increasing the relative fraction of $\mathrm{Pu}$ in the mixture from $10^{\mathrm{v}} \%$ to $16^{\mathrm{v}} \%$ improves the Pu incineration efficiency by a factor of $\sim 2$ for both cycles by (more than) doubling the discharge burnups, and improves the Pu utilization by more than $19 \%$ and $25 \%$ for the MOX and TOX cycles, respectively.

2. The incineration performance of the TOX fuel cycle is superior to that of MOX. The percentage of Pu burnt per pass can be as high as $30 \%$ and $50 \%$ in the MOX and TOX fuel cases, respectively.

3. The fraction of heat-producing nuclides in discharged fuel (i.e. ${ }^{238} \mathrm{Pu}$ and ${ }^{241} \mathrm{Pu}$ ) is much higher in the TOX case, which improves the proliferation resistance of the spent fuel.

\subsection{Determination of Pu loading limits}

Increasing the Pu content in either MOX or TOX helps improve various fuel cycle performance metrics (e.g. economics and fuel utilization). However, the reactor physics characteristics of Pu fuel cycles are different from those of typical $\mathrm{UO}_{2}$ cycles (Shwageraus et al., 2003; Galperin et al., 2000). More specifically, high Pu content significantly hardens the spectrum (Fig. 7), which reduces the reactivity worth of various control materials, such as ${ }^{10} \mathrm{~B}$ (Fig. 8). Increasing the Pu content in the mixture results in higher excess reactivity, which requires higher boron content in the coolant to maintain core criticality. High boron concentration in the coolant directly impacts the MTC, which eventually becomes positive, as shown in Fig. 9. In conventional PWR cores the amount of $\mathrm{Pu}$ that can be loaded can be limited by the need to avoid a positive void coefficient. However, as the $\mathrm{I}^{2} \mathrm{~S}$-LWR integral design eliminates the possibility of a large-break loss of coolant accident (LOCA), there is no plausible accident scenario in which the core

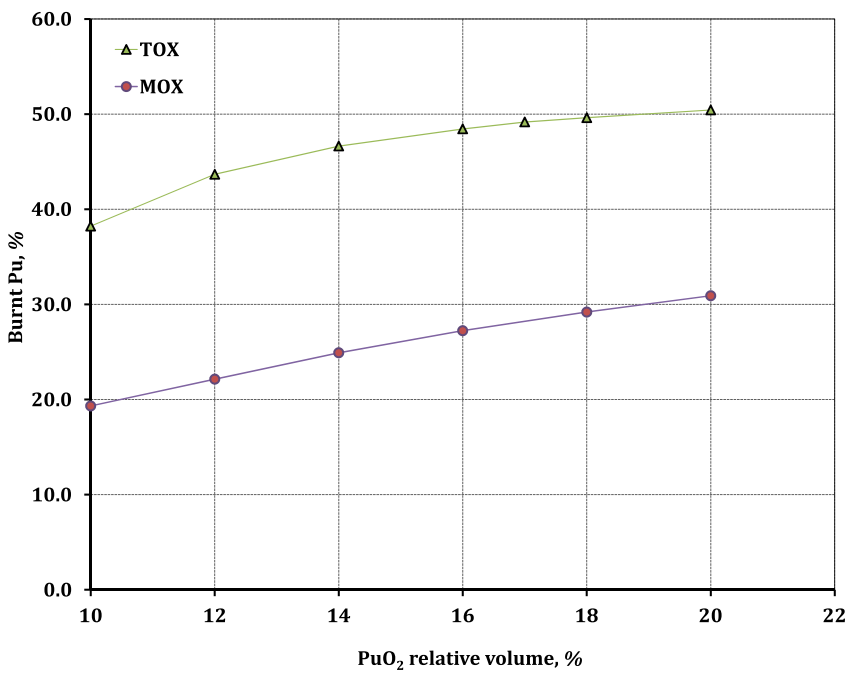

Fig. 6. Amount of Pu burnt (\%) as a function of initial $\mathrm{PuO}_{2}$ volume (vo). 
Table 3

Summary of fuel cycle performance for the TOX and MOX cycles.

\begin{tabular}{|c|c|c|c|c|}
\hline & \multicolumn{2}{|c|}{$10^{v_{\%}} \mathrm{PuO}_{2}$} & \multicolumn{2}{|c|}{$16^{\mathrm{v}_{\%}} \mathrm{PuO}_{2}$} \\
\hline & MOX & TOX & MOX & TOX \\
\hline Discharge burnup (MWd/kg) & 42.3 & 42.9 & 79.8 & 90.9 \\
\hline Pu burnt, (\%) & 19.3 & 38.2 & 27.2 & 48.4 \\
\hline Discharged $\mathrm{Pu}^{238+241} / \mathrm{Pu}(\%)$ & 44.5 & 77.7 & 46.9 & 76.4 \\
\hline Pu utilization (kg-Pu/MWe-yr) & 3.1 & 3.2 & 2.5 & 2.4 \\
\hline
\end{tabular}

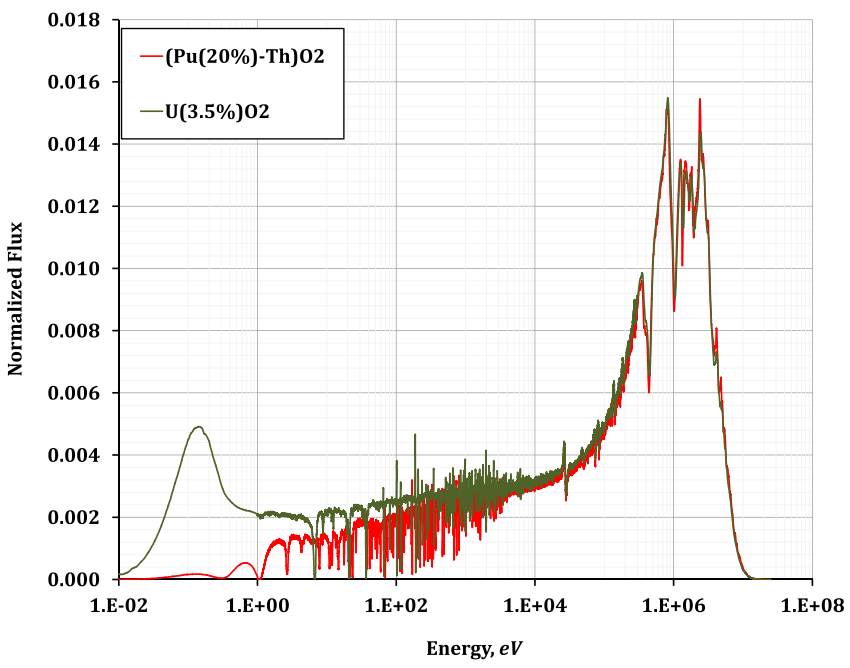

Fig. 7. Neutron spectrum comparison $(\mathrm{Pu}-\mathrm{Th}) \mathrm{O}_{2}\left(20^{\mathrm{v}} \% \mathrm{PuO}_{2}\right)$ vs. typical $\mathrm{UO}_{2}$ $\left(3.5^{\mathrm{w}} \%{ }^{235} U\right)$.

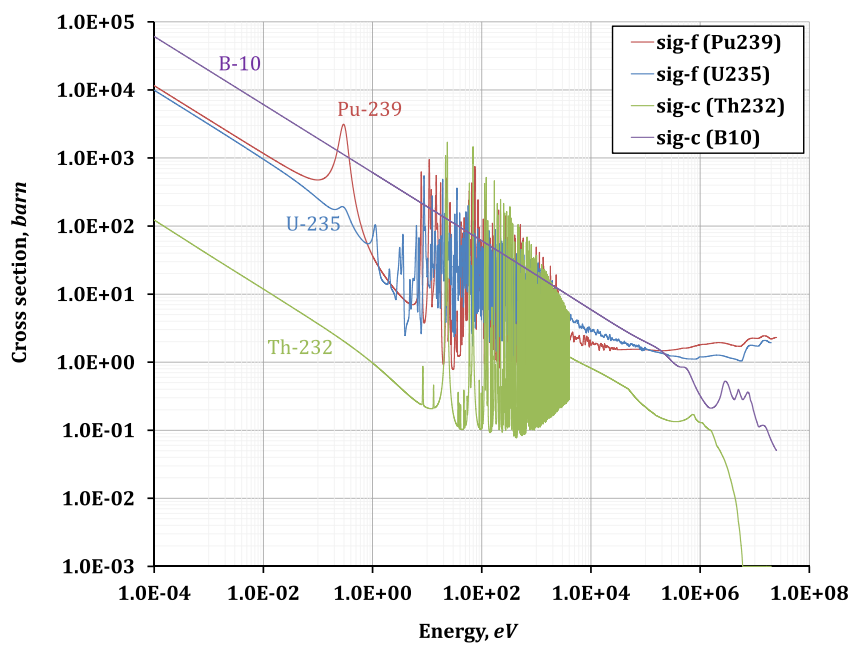

Fig. 8. Energy-dependent cross-sections for various nuclides.

would be substantially voided, and therefore negative MTC rather than void coefficient is used as the limiting condition in this study.

In this section, we identify the practical initial Pu loading for both TOX and MOX fuel cycles in the $\mathrm{I}^{2} \mathrm{~S}-\mathrm{LWR}$. This is done by examining the effect of Pu loadings on the MTC, as depicted in Fig. 9. Each point in this figure was obtained by conducting full $3 \mathrm{D}$ core calculations and iteratively reaching the equilibrium cycle. The PANTHER code provides a built-in capability for the evaluation of reactivity coefficients.

Fig. 9 shows the beginning-of-cycle (BOC) core MTC as a function of $\mathrm{PuO}_{2}$ volume fraction. As shown in the next section, the

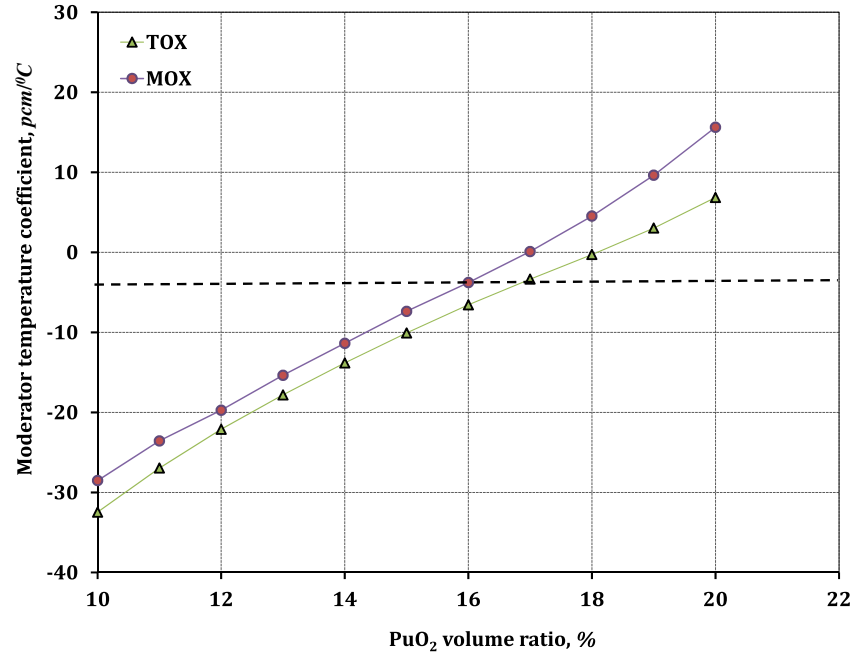

Fig. 9. Core MTC at beginning of cycle as a function of Pu content.

MTC becomes more negative over the course of the cycle, so the BOC MTC represents the limiting case.

The MTC is defined as the change in reactivity per one degree change in the moderator temperature, and is calculated using Eq. (2):

$\mathrm{MTC}=\frac{k_{\text {ref }}-k_{\text {per }}}{k_{\text {ref }} \times k_{\text {per }} \times\left(T_{\text {ref }}-T_{\text {per }}\right)}$

where $k_{\text {ref }}$ and $k_{\text {per }}$ are the reference and perturbed criticality values that correspond to the temperatures $T_{\text {ref }}$ and $T_{\text {per }}$, respectively. The inlet coolant temperature was perturbed by $5^{\circ} \mathrm{C}$ for the purposes of these calculations.

Fig. 9 shows that as the volume of $\mathrm{PuO}_{2}$ increases the BOC MTC for both cycles, eventually becomes positive. However, in order to conduct a fair comparison (Section 4.4), the volume of $\mathrm{PuO}_{2}$ for the TOX and MOX cores was chosen to be $17^{\mathrm{v}} \%$ and $16^{\mathrm{v}} \%$, respectively. These values were chosen since they correspond to approximately the same small negative BOC MTC value in both cases.

\subsection{Equilibrium TOX and MOX homogeneous cycle core analysis}

This section reports on the results of the full-core steady-state analysis for the $17^{\mathrm{v}_{\%}} \%$ TOX and $16^{\mathrm{v}} \%$ MOX Pu loaded cores mentioned in the previous section. At this stage, the loading pattern was fixed as stated in Section 3. In addition, an identical 3-batch fuel management strategy was applied to both cores.

The variation of critical boron concentration (CBC) over the course of a cycle for the two cores is shown in Fig. 10. It can be seen that for both (TOX and MOX) cases the CBC is below 2000 ppm, as mandated by operational requirements. It should be noted that the boron (in nature $20 \%{ }^{10} \mathrm{~B}$ ) was assumed to be enriched to $90 \%{ }^{10} \mathrm{~B}$ to counteract the reduced boron worth.

The power peaking factors (Fig. 11) for the TOX fuel are within acceptable limits and are similar (e.g. 1.8 at BOC) to those obtained in the original $\mathrm{I}^{2} \mathrm{~S}$-LWR fuel cycle. In the MOX case, the total power peaking factor at BOC is higher $(\sim 1.96)$ and will probably necessitate a further reduction in the initial Pu loading.

The difference in initial power peaking factors can be attributed to the more moderate reactivity change in the TOX case, which creates a flatter power distribution within the core.

The reactivity coefficients are shown in Figs. 12 and 13. The MTCs are negative throughout and the curves for the TOX and MOX cases are similar. The MTC values for both of the cycles are higher (i.e. less negative) than typical values for $\mathrm{UO}_{2}$ fueled PWRs. 


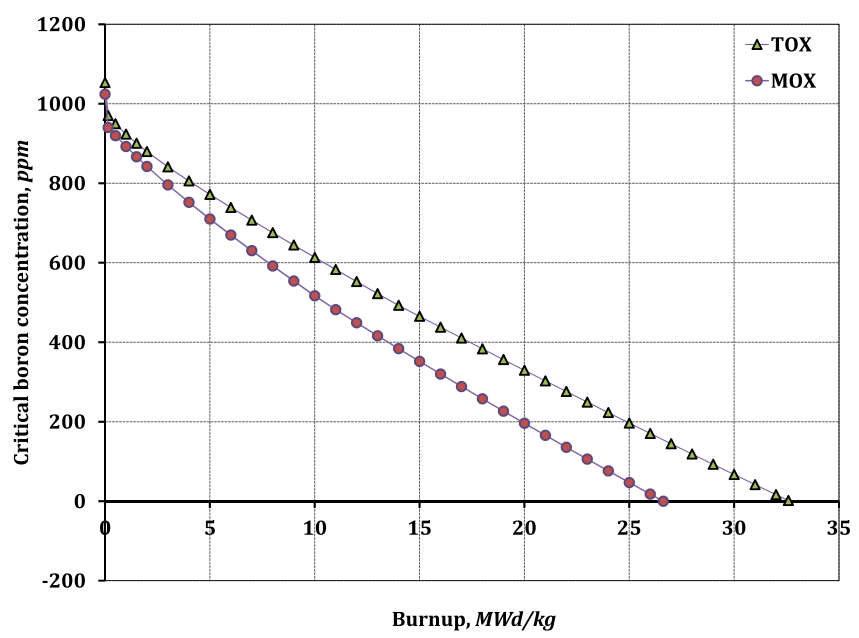

Fig. 10. Critical boron letdown curves.

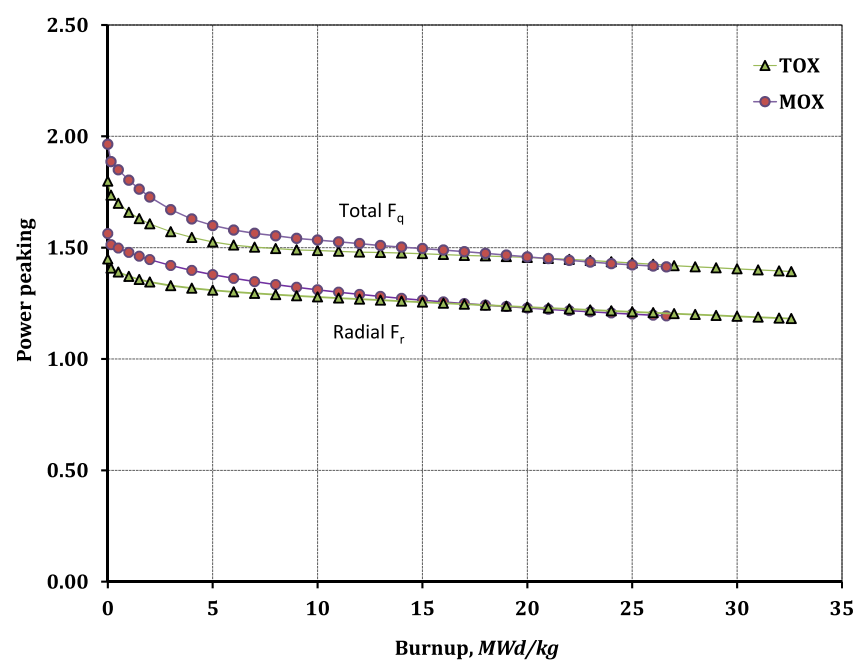

Fig. 11. Power peaking values as a function of burnup.

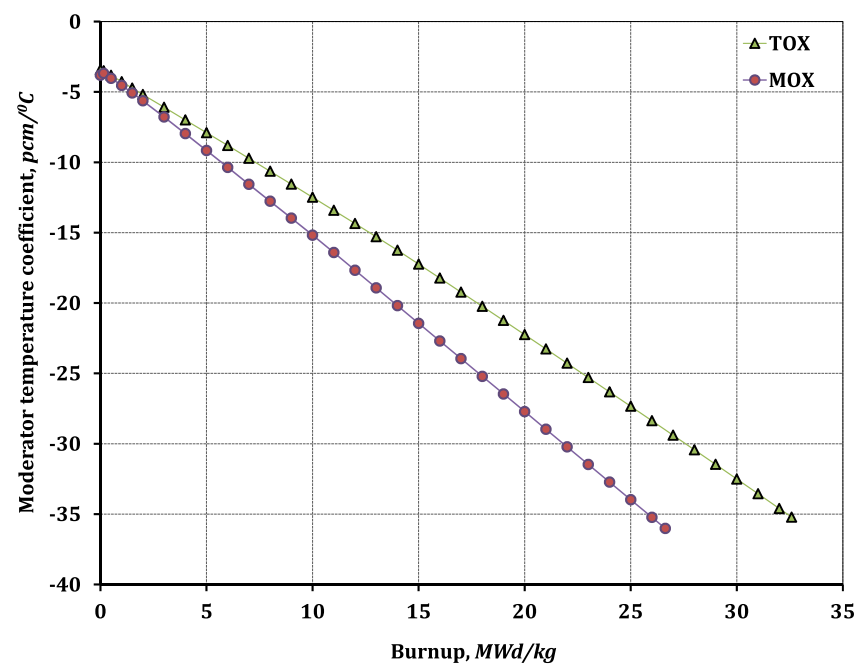

Fig. 12. Moderator temperature coefficients as a function of burnup.

This leads to a lower power defect and would be beneficial (make it easier) to provide the necessary shutdown margins. In addition,

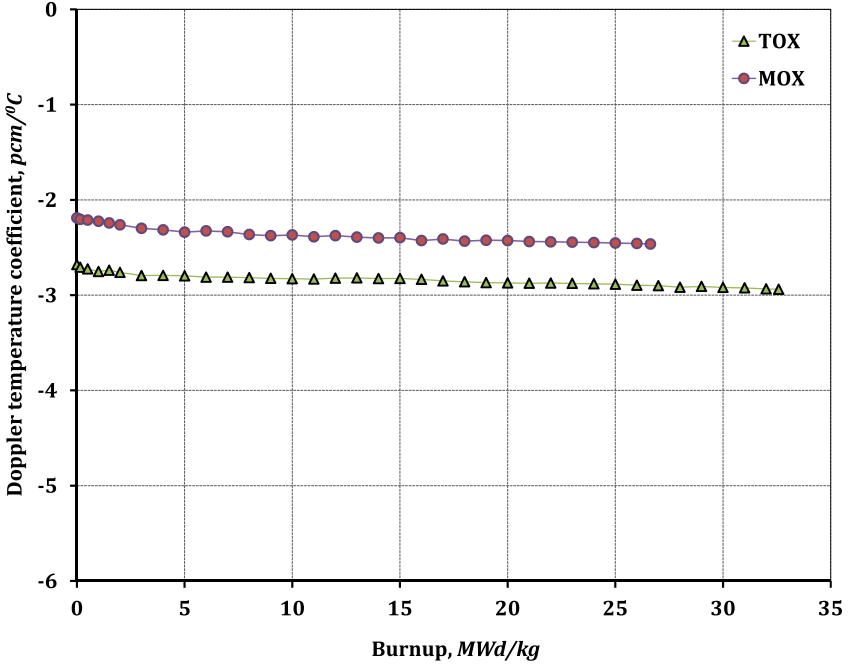

Fig. 13. Doppler coefficients as a function of burnup.

Fig. 13 shows that the Doppler coefficient (DC) is more negative in the TOX case. The DC was calculated using Eq. (2).

The $\mathrm{Pu}$ and the transuranic (TRU) incineration efficiencies for the MOX and TOX cores are reported in Table 4. In the TOX core, the higher initial $\mathrm{Pu}$ loading enables the irradiation period to be extended. As expected, the Pu burning efficiency of the TOX fuel is significantly higher than (almost double) that of the MOX fuel. Although considerably less $\mathrm{Pu}$ is generated in the TOX core, ${ }^{233} \mathrm{U}$ is being bred from ${ }^{232} \mathrm{Th}$. Hence, the overall TRU destruction rates in the TOX core are higher only by a factor of 1.5 .

Finally, a summary of the reactivity coefficients at BOC and end of cycle (EOC) for the cases considered is presented in Table 5. Boron worth (BW) values are included alongside DC and MTC values. An additional set of calculations was carried out for the original $\mathrm{I}^{2} \mathrm{~S}$-LWR core (Petrovic, 2014) with $\mathrm{U}_{3} \mathrm{Si}_{2}$ fuel. This case is denoted as 'REF' because it provides a point of reference for consistent cross-comparison between the different cases.

\subsection{Assessment of TOX and MOX safety margin to melting}

The core results presented in previous sections concluded that the TOX fuel cycle is feasible for the $\mathrm{I}^{2} \mathrm{~S}$-LWR and can be used to achieve a set of specific goals. Moreover, TOX fuel exhibits better performance than MOX with respect to the objectives of achieving a longer fuel cycle and higher Pu disposition rate.

This section demonstrates an additional inherent safety advantage of the TOX fuel cycle. More specifically, its safety margin to fuel melting is presented.

For this purpose, 4 different fuel options $\left(\mathrm{U}_{3} \mathrm{Si}_{2}, \mathrm{UO}_{2}, \mathrm{MOX}\right.$ and TOX) were investigated here. It must be noted that the pellet geometry for the $\mathrm{U}_{3} \mathrm{Si}_{2}$ case is different (Salazar and Franceschini, 2014) from the others mainly due to its central void region to accommodate the higher swelling rate of the $U_{3} \mathrm{Si}_{2}$ fuel. For each

Table 4

$\mathrm{Pu}$ and TRU incineration performance.

\begin{tabular}{|c|c|c|}
\hline & MOX & TOX \\
\hline Initial Pu (kg/assembly) & 101.05 & 107.05 \\
\hline Discharge burnup (MWd/kg) & 79.8 & 97.8 \\
\hline Pu burnt $(\%)$ & 27.8 & 49.2 \\
\hline $\mathrm{EOC} \mathrm{Pu}^{238+241} / \mathrm{Pu}(\%)$ & 46.9 & 76.4 \\
\hline TRU burnt $^{1}(\%)$ & 22.8 & 33.6 \\
\hline
\end{tabular}

$1^{233} \mathrm{U}$ and ${ }^{233} \mathrm{~Pa}$ were included in the TRU inventory. 
Table 5

Summary of core reactivity coefficients.

\begin{tabular}{|c|c|c|c|c|c|c|c|c|c|}
\hline & \multicolumn{3}{|c|}{$\mathrm{DC}\left(\mathrm{pcm} /{ }^{\circ} \mathrm{C}\right)$} & \multicolumn{3}{|c|}{$\operatorname{MTC}\left(\mathrm{pcm} /{ }^{\circ} \mathrm{C}\right)$} & \multicolumn{3}{|c|}{$\mathrm{BW}(\mathrm{pcm} / \mathrm{ppm})$} \\
\hline & REF & MOX & TOX & REF & MOX & TOX & REF & MOX & TOX \\
\hline $\mathrm{BOC}$ & -2.52 & -2.19 & -2.68 & -19.2 & -3.8 & -3.4 & -5.1 & -6.3 & -6.5 \\
\hline $\mathrm{EOC}$ & -3.10 & -2.49 & -2.94 & -51.2 & -36.0 & -35.2 & -5.7 & -7.6 & -7.8 \\
\hline
\end{tabular}

case, a 3D assembly model was used to simulate rapid overpower events. The analyses relied on coupled neutronic-thermal-hydrau lic calculations and were performed with PANTHER. Table 6 details the melting temperature, $T_{M}$, and thermal conductivity of the considered fuel types. The melting points and thermal conductivities for $\mathrm{UO}_{2}$ and MOX were taken from Popov et al. (2000). The thermal properties for $\mathrm{U}_{3} \mathrm{Si}_{2}$ were obtained from Samoilov et al. (1968). The thermal conductivity and the fuel melting temperature for the TOX were obtained from Cozzo et al. (2011) and Bohler et al. (2015), respectively.

Typically, fuel melting safety margins are defined as the difference between the maximum fuel temperature at normal operation and the melting temperature. However, previous studies (Ferroni et al., 2014) have indicated that this definition cannot adequately account for the effect of the fuel thermal conductivity. For example, for two fuel types with the same margin to melting (according to this definition of margin), the one with higher thermal conductivity would be preferable because it could tolerate a higher power increase before reaching its melting point.

In our analysis, the assembly average power was increased in order to find the overpower factor causing the maximum fuel temperature to reach the fuel melting point. This factor is representative of the safety margin to fuel melting, since it captures the effects both of the maximum fuel temperature during full power normal operation and the ease with which fuel melting conditions can then be reached.

Results are shown in Fig. 14, which presents the overpower factor of the different fuels. The results indicate that the overpower factor of the TOX fuel is larger than that of all the others, due to its high melting point and relatively high conductivity values.

\section{Summary}

The main objective of this study was to analyse the homogeneous Th-Pu oxide (TOX) fuel cycle for the $\mathrm{I}^{2} \mathrm{~S}$-LWR design. Adopting the TOX cycle facilitates longer fuel burnups that cannot be matched by either the $\mathrm{UO}_{2}$ or $\mathrm{U}_{3} \mathrm{Si}_{2}$ fuel cycles due to the $\mathrm{U}$ enrichment limitation. The new $\mathrm{I}^{2} \mathrm{~S}$-LWR cladding material is believed to be suitable for the goal of achieving high burnups. However, the reactor physics characteristics of the $\mathrm{Pu}$ fuel cycle are different from those of typical $\mathrm{UO}_{2}$ fuel. For example, the worth of control material (e.g. boron) would be significantly lower due to the presence of $\mathrm{Pu}$, which is a strong thermal absorber.

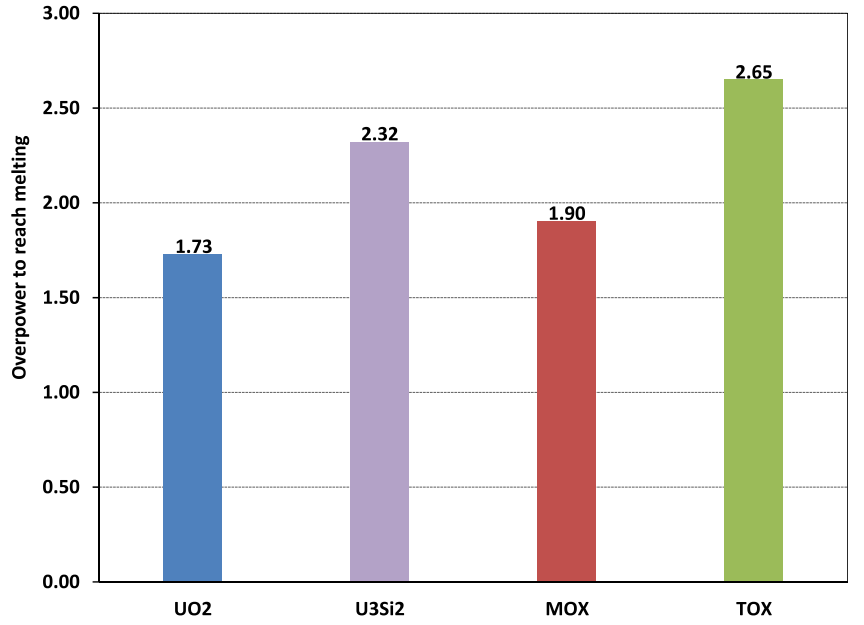

Fig. 14. Overpower factor to reach melting for the different fuels.

The current work illustrated some of the challenges of the $\mathrm{Pu}$ cycle (Section 4.2), the main one of which is ensuring a negative MTC, along with prohibitively high critical boron concentrations. While the $\mathrm{CBC}$ issues can be solved fairly easily by enriching the soluble boron, a careful core design process is required to ensure an acceptable MTC. Therefore, the first design stage here was to adopt a loading pattern that minimizes the value of the MTC. The next stage was to establish the maximum fraction of $\mathrm{Pu}$ in the fuel which ensures that all reactivity control and power peaking design limits are not violated. To satisfy these safety criteria, the TOX and MOX cores were loaded with $17^{v_{\%}}$ and $16^{\mathrm{v}} \%$ of $\mathrm{PuO}_{2}$, respectively. The higher initial Pu content enhances the performance of the TOX core (compared to that of the MOX core) even further. The advantages of the TOX fuel cycle are expressed in considerably higher burnup, improved Pu incineration efficiency and enhanced safety features.

There is an additional reason why the proposed $\mathrm{Pu}-\mathrm{Th}$ fuel cycle is particularly suitable for the $\mathrm{I}^{2} \mathrm{~S}-\mathrm{LWR}$ design. In general, increasing the discharge burnup results in higher fission gas release. The original design uses $\mathrm{U}_{3} \mathrm{Si}_{2}$ (rather than $\mathrm{UO}_{2}$ ) fuel. $\mathrm{U}_{3} \mathrm{Si}_{2}$ is expected to experience higher fission gas accumulation at crystalline grain boundaries, which gradually migrates by diffusion. The $\mathrm{I}^{2} \mathrm{~S}$-LWR fuel pins gas plena were therefore increased in

Table 6

Thermal properties of the considered fuel types.

\begin{tabular}{|c|c|c|}
\hline & $T_{M}, \mathrm{~K}$ & Thermal conductivity, $\mathrm{Wm}^{-1} \mathrm{~K}^{-1}$ \\
\hline $\mathrm{UO}_{2}$ & 3113 & $-1.526 \times 10^{-15} T^{5}+1.057 \times 10^{-11} T^{4}-2.745 \times 10^{-8} T^{3}+3.415 \times 10^{-5} T^{2}-2.217 \times 10^{-2} T+9.343$ \\
\hline $\mathrm{U}_{3} \mathrm{Si}_{2}$ & 1938 & $8.155+8.35 \times 10^{-3} T$ \\
\hline \multirow[t]{2}{*}{ MOX } & 3023 & $\begin{array}{l}\frac{1.1579}{A+C T}+2.3434 \times 10^{11} T^{-\frac{5}{2}} e^{-\frac{16350}{T}} \\
A(x)=2.85 x+0.035\end{array}$ \\
\hline & & $C(x)=(-7.15 x+2.86) \times 10^{-4}$ \\
\hline \multirow[t]{2}{*}{ TOX } & 3484 & $\frac{1}{A+2.4 \times 10^{-4} T}\left(1-0.05\left(2.6-\frac{0.5 T}{1000}\right)\right)$ \\
\hline & & $A(x)=6.071 \times 10^{-3}+0.572 x-0.5937 x^{2}$ \\
\hline
\end{tabular}


size. This design feature is extremely useful in helping to achieve longer irradiation periods, as in the case of the proposed $\mathrm{Pu}-\mathrm{Th}$ fuel cycle.

To conclude, this study of the Pu-Th fuel cycle for the $\mathrm{I}^{2} \mathrm{~S}-\mathrm{LWR}$ shows the attractiveness of high Pu contents to achieve better fuel utilization and reduced volume of high level waste.

\section{Data availability statement}

To the best of the authors' knowledge this paper and references herein contain all the data needed to reproduce and validate the results presented.

\section{Acknowledgements}

This research was sponsored by the UK Engineering and Physical Sciences Research Council (EPSRC) under grant EP/K033611/1.

\section{References}

Bjork, K., Fhager, V., 2009. Comparison of thorium-plutonium fuel and MOX fuel for PWRs. Proc of GLOBAL Paris, France.

Bohler, R., Cakir, P., Benes, O., Konings, R., Manara, D., 2015. High temperature phase transition of mixed $\mathrm{PuO}_{2}+\mathrm{ThO}_{2}$ investigated by laser melting. J. Chem. Thermodyn. 81, 245-252.

Cozzo, C., Staicu, D., Somers, J., Fernandez, A., Konings, R., 2011. Thermal diffusivity and conductivity of thorium-plutonium mixed oxides. J. Nucl. Mater. 416, 135141.

Feinroth, H., Hao, B., Fehrenbacher, L., Patterson, M., 2002. Progress in developing an impermeable, high temperature ceramic composite for advanced reactor clad and structural applications. In: Proc. ICAPP 2002, Hollywood, Florida, USA.

Ferroni, P., Sjoden, G., Chin, M., 2014. Preliminary thermal-hydraulic feasibility evaluation of the integral inherently safe LWR ( ${ }^{2} S$-LWR) high power density core. In: International Congress on the Advances in Nuclear Power Plants ICAPP, Charlotte, NC, USA.

Fridman, E., Kliem, S., 2011. Pu recycling in a full Th-MOX PWR core Part I: steady state analysis. Nucl. Eng. Des. 241, 193-202.

Galperin, A., Raizes, G., 1997. A pressurized water reactor design for plutonium incineration: fuel cycle options. Nucl. Technol. 117, 125-132.
Galperin, A., Segev, M., Todosow, M., 2000. A pressurized water reactor plutonium incinerator based on thorium fuel and seed-blanket assembly geometry. Nucl. Technol. 132, 214-226.

IAEA, 1998. Communication received from certain member states concerning their policies regarding the management of plutonium. Information Circular INFCIRC/ 549. International Atomic Energy Agency. Vienna, Austria.

IAEA, 2003. Status and advances in MOX fuel technology.,Technical Report, number STI/DOC/010/415. International Atomic Energy Agency.Vienna, Austria.

Laughter, M., Hejzlar, P., Kazimi, M., 2002. Self-protection characteristics of Uranium-233 in the ThO2-UO2 PWR fuel cycle. Technical Report. Massachusetts Institute of Technology. Cambridge, Massachusetts, USA.

Lindley, B.A., Kotlyar, D., Parks, G.T., Lillington, J.N., Petrovic, B., 2016. Reactor physics modelling of accident tolerant fuel for LWRs using ANSWERS codes. EPJ Nucl. Sci. Technol. 2, 1-9.

Morrison, A., 2003. PANTHER User Guide., Technical Report., British Energy. Barnwood, United Kingdom.

Newton, T., Hosking, G., Hutton, L., Powney, D., Turland, B., Shuttleworth, E., 2008. Developments within developments within WIMS10. Proc PHYSOR Interlaken, Switzerland.

Parks, G., 1996. Multiobjective pressurized water reactor reload core design by nondominated genetic algorithm search. Nucl. Sci. Eng. 124, 178-187.

Petrovic, B., 2014. Integral inherently safe light water reactors $I^{2} S$-LWR concept: extending SMR safety features to large power output. Proc. ICAPP 2014 Charlotte, North Carolina, USA.

Petrovic, B., submitted for publication. The integral inherently safe LWR I ${ }^{2} S$-LWR: Overview of an innovative concept. Ann. Nucl. Energy.

Popov, S., Ivanov, V., Carbajo, J., Yoder, G., 2000. Thermophysical properties of MOX and $\mathrm{UO}_{2}$ fuels including the effects of irradiation. Technical Report ORNL/TM2000/351. Oak Ridge National Laboratory. Oak Ridge, Tennessee, p. 37831.

Salazar, D., Franceschini, F., 2014. I $^{2}$ S-I ${ }^{2}$ S-LWR equilibrium cycle core analysis. Proc. PHYSOR 2014, Kyoto, Japan.

Samoilov, A., Kashtanov, A., Volkov, V., 1968. Dispersion-fuel nuclear reactor elements (1965)., Technical Report. Israel Program for Scientific Translations Ltd. Jerusalem, Israel.

Shwageraus, E., Feinroth, H., 2011. Potential of silicon carbide cladding to extend burnup of Pu-Th mixed oxide fuel. In: Trans. American Nuclear Society (ANS) Annual Meeting, Hollywood, Florida, USA, pp. 658-660.

Shwageraus, E., Hejzlar, P., Kazimi, M.S., 2003. Use of thorium for transmutation of plutonium and minor actinides in PWRs. Nucl. Technol. 147, 53-68.

Terrani, K., Keiser, J., Brady, M., Cheng, T., Silva, G., Pint, B., Snead, L., 2012. High temperature oxidation of silicon carbide and advanced iron-based alloys in steam-hydrogen environments. Proc. TopFuel 2012, Manchester, United Kingdom.

Zainuddin, N., 2015. In-core Optimisation of Thorium-Plutonium-Fuelled PWR Cores (PhD Thesis). 